E3S Web of Conferences 1, 26006 (2013)

DOI: $10.1051 / \mathrm{e} 3$ sconf/20130126006

(C) Owned by the authors, published by EDP Sciences, 2013

\title{
Arsenic metabolites in humans after ingestion of wakame seaweed
}

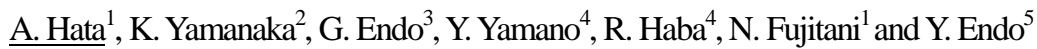 \\ ${ }^{1}$ Division of Clinical Laboratory Science, Department of Medical Risk Management, Faculty of Risk and Crisis Management, Chiba \\ Institute of Science, Chiba, Japan; ahata@cis.ac.jp, nfujitani@cis.ac.jp \\ ${ }^{2}$ Research Unit of Environmental Toxicology and Carcinogenesis, School of Pharmacy, Nihon University, Chiba, Japan; \\ yamanaka.kenzo@nihon-u.ac.jp \\ ${ }^{3}$ Department of Preventive Medicine and Environmental Health, Graduate School of Medicine, Osaka City University, Osaka, Japan; \\ endog@med.osaka-cu.ac.jp \\ ${ }^{4}$ Department of Hygiene and Preventive Medicine, School of Medicine, Showa University, Tokyo, Japan; yamano@med.showa-u.ac.jp, \\ haba@med.showa-u.ac.jp \\ ${ }^{5}$ Research Center for Occupational Poisoning, Kansai Rosai Hospital, Japan Labour Health and Welfare Organization, Hyogo, Japan; \\ yokoendo@kanrou.net
}

\begin{abstract}
Seaweed contains large amounts of various arsenic compounds such as arsenosugars (AsSugs), but their relative toxicities have not yet been fully evaluated. A risk evaluation of dietary arsenic would be necessary. After developing an arsenic speciation analysis of wakame seaweed (Undaria pinnatifida), we conducted a wakame ingestion experiment using volunteers. Five volunteers ingested $300 \mathrm{~g}$ of commercial wakame after refraining from seafood for 5 days. Arsenic metabolites in the urine were monitored over a 5-day period after ingestion. Total arsenic concentration of the wakame seaweed was $34.3 \pm 2.1 \mathrm{mg}$ arsenic/kg (dry weight, $\mathrm{n}=3$ ). Two AsSugs, 3-[5'-deoxy-5'-(dimethyl-arsinoyl)- $\beta$-ribofuranosyloxy]-propylene glycol (AsSug328) and 3-[5'-deoxy-5'-(dimethyl-arsinoyl)- $\beta$ - ribofuranosyl-oxy]-2-hydroxypropyl-2,3-dihydroxy-propyl phosphate (AsSug482) were detected, but arsenobetaine, dimethylarsinic acid (DMA), monomethylarsonic acid, and inorganic arsenics (iAs) were not detected. The major peak was AsSug 328 , which comprised $89 \%$ of the total arsenic. Approximately $30 \%$ of the total arsenic ingested was excreted in the urine during the 5-day observation. Five arsenic compounds were detected in the urine after ingestion, the major one being DMA, which comprised $58.1 \pm 5.0 \%$ of the total urinary arsenic excreted over the 5 days. DMA was believed to be metabolized not from iAs but from AsSugs, and its biological half-time was approximately $13 \mathrm{~h}$.
\end{abstract}

Keywords: arsenosugar, metabolite, organoarsenic, seaweed, urine

\section{Introduction}

The International Agency for Research on Cancer (IARC) has concluded that sufficient epidemiological evidence exists regarding the carcinogenicity of inorganic arsenic (iAs) in the human lung, skin, and urinary bladder (IARC, 2004). The methylation of inorganic arsenic to monomethylarsonic acid (MMA) and dimethylarsinic acid (DMA) has been demonstrated in humans and several mammalian species (Vahter, 2002). These metabolites are less reactive with tissue constituents than iAs and are readily excreted in the urine. However, reactive intermediates of trivalent MMA and DMA $\left(\mathrm{MMA}^{\mathrm{III}}\right.$ and $\mathrm{DMA}^{\mathrm{III}}$ ) produced in the metabolic processing of iAs in mammals may be responsible for the observed carcinogenic action (Yamanaka et al., 2004; Mizoi et al., 2005). Therefore, the IARC has classified MMA and DMA into Group 2B and arsenobetaine (AsBe) and other organic arsenic compounds that are not metabolized in humans into Group 3 (IARC, 2010).
Seafood contains high levels of organoarsenic compounds such as AsBe, DMA, arsenocholine (AsCho), arsenosugars (AsSugs), and arsenolipids (AsLip) (Kirby et al., 2005; Taleshi et al., 2010). AsSugs and AsLip are extensively metabolized to DMA(Francesconi et al., 2002; Schmeisser et al., 2006).

Therefore, as the intake of AsSugs, the major watersoluble organic arsenic compounds in seaweed, might pose a risk to human health, we attempted to measure urinary arsenic metabolites after seaweed ingestion by human volunteers.

\section{Materials and Methods}

Test seafood

Commercial dry wakame seaweed (Undaria pinnatifida) was purchased from a retail market in Chiba, Japan, and dipped in deionized water for $30 \mathrm{~min}$ prior to ingestion. 


\section{Determination of total arsenic content in wakame seaweed}

The total arsenic (T-As) content in wakame samples were analyzed with inductively coupled mass spectrometry (ICPMS) using the dynamic reaction cell (DRC) mode (Elan DRCII ICP-MS; PerkinElmer SCIEX, Canada) after microwave acid digestion using a closed vessel system (Multiwave 3000; PerkinElmer SCIEX). The digested solution was measured using the standard addition method. Instrumental conditions for ICP-MS using the DRC mode were described in our earlier report (Shimoda et al., 2010). The method was validated by analysis of DORM-3 (fish protein from the National Research Council of Canada) (certified T-As $=6.88 \pm 0.88 \mu \mathrm{g} / \mathrm{g}$; found $\mathrm{T}$-As $=6.91 \pm 0.26 \mu \mathrm{g} / \mathrm{g}, n=3)$.

\section{Extraction of arsenic from wakame seaweed}

Prior to the ingestion experiment, we determined a suitable method to extract arsenic from seaweed. Methanol (50\%) was used to extract arsenic compounds from the wakame seaweed. After cellulase treatment, we applied 3 physical procedures as extraction procedures: bead beating, ultrasonication, and shaking.

\section{Ingestion of wakame seaweed and collection of urine samples}

Five Japanese volunteers ( 2 men and 3 women; $21 \pm 0.7$ years old) ingested $300 \mathrm{~g}$ of wakame seaweed. The volunteers refrained from eating seafood 5 days prior to and during the course of the experiment. Arsenic metabolites in the urine were monitored before and up to $120 \mathrm{~h}$ after ingestion.

\section{Analytical conditions}

Arsenic species determination was performed using highperformance liquid chromatography (HPLC)-ICP-MS systems. We used a PRP-X100 $(250 \times 2.1 \mathrm{~mm}$ i.d.; Hamilton, USA $)$ anion-exchange column to separate the arsenic compounds under the following conditions: mobile phase, $20 \mathrm{mM}$ $\mathrm{NH}_{4} \mathrm{HCO}_{3}$ (pH 9.0); flow rate, $0.2 \mathrm{~mL} / \mathrm{min}$; column temperature, $40^{\circ} \mathrm{C}$; and injection volume, $10 \mu \mathrm{L}$. Detection of AsSugs in wakame seaweed was performed using MS/MS spectra and multiple reaction monitoring (MRM) using an amaZon SL ion trap tandem mass spectrometer (Bruker Daltonics, USA) with an electrospray ionization positive-ion mode. HPLC analytical conditions were the same as above.

MRM was optimized to detect collision-induced dissociation fragmentations of the selected arsenic compounds (Table 1).

Tab.1 The fragmentation parameters of multiple-reaction monitoring for arsenic compounds

\begin{tabular}{ccccc}
\hline Compounds & $\begin{array}{c}\text { Precursor ion } \\
(\mathbf{m} / \mathbf{z})\end{array}$ & \multicolumn{2}{c}{$\begin{array}{c}\text { Product ion } \\
(\mathbf{m} / \mathbf{z})\end{array}$} & $\begin{array}{c}\text { Collision } \\
\text { energy (V) }\end{array}$ \\
\hline DMA & 139 & 109 & 91 & 0.3 \\
TMAO & 137 & 122 & 107 & 0.3 \\
AsCho & 165 & 121 & 105 & 0.3 \\
AsBe & 179 & 120 & - & 0.5 \\
AsSug328 & 329 & 237 & 97 & 0.5 \\
AsSug391 & 392 & 237 & 97 & 0.5 \\
AsSug392 & 393 & 237 & 97 & 0.5 \\
AsSug408 & 409 & 237 & 97 & 0.5 \\
AsSug482 & 483 & 237 & 97 & 0.5 \\
\hline
\end{tabular}

The molecular structures of the selected arsenic compounds are shown in Fig. 1.

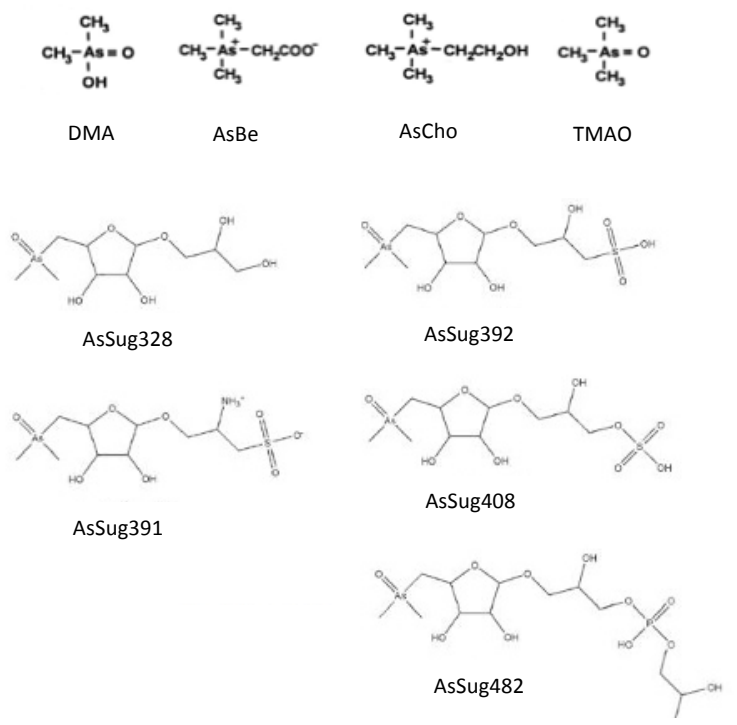

Fig.1 The molecular structures of the selected arsenic compounds

\section{Results and Discussion}

Determination of total arsenic and speciation analysis of wakame seaweed

The T-As concentration of dry wakame seaweed was $34.31 \pm$ $2.10 \mu \mathrm{g} \mathrm{As} / \mathrm{g}(\mathrm{n}=3)$. The arsenic contents extracted using the 3 methods are listed in Table 2. Extraction using the bead beating method produced the highest yield and the extraction rate was $92 \%$. This result indicates that $>90 \%$ of arsenic compounds in dry seaweed are water-soluble organoarsenic compounds.

A chromatogram of the arsenic speciation analysis of wakame seaweed by HPLC-ICP-MS is depicted in Figure 2a. Three peaks were detected, but three peaks did not correlate with AsBe, DMA, MMA, trimethylarsine oxide, AsCho, or iAs. In HPLC-MS/MS analysis using MRM techniques, we detected AsSug328 and AsSug482, as shown in Figure 2b, but AsSug391, AsSug392, and AsSug408 were not detected. The major peak was AsSug328, which comprised $88.8 \%$ of T-As.

Tab. 2 The extraction rates of the 3 methods

\begin{tabular}{cccc}
\hline $\begin{array}{c}\text { Total } \\
\text { arsenic }\end{array}$ & Bead beating & $\begin{array}{c}\text { Ultra- } \\
\text { sonication }\end{array}$ & Shaking \\
\hline $34.31 \pm 2.10$ & $\begin{array}{c}31.53 \pm 4.98 \\
(91.9 \%)\end{array}$ & $\begin{array}{c}25.26 \pm 5.51 \\
(73.6 \%)\end{array}$ & $\begin{array}{c}14.13 \pm 1.37 \\
(41.2 \%)\end{array}$ \\
\hline Values in parentheses mean recovery rate & unit: $\mathrm{mg} \mathrm{As} / \mathrm{kg}$
\end{tabular}


(a)

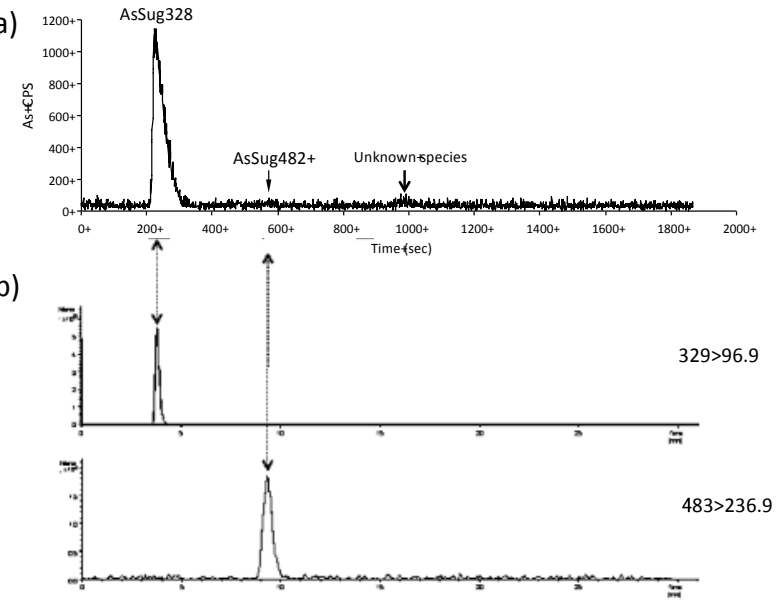

Fig.2 Chromatogram of arsenic speciation analysis of wakame seaweed using high-performance liquid chromatography (HPLC) inductively coupledplasma (ICP) massa spectrometry (MS) (a) and HPLC tandem MS/MS (b)

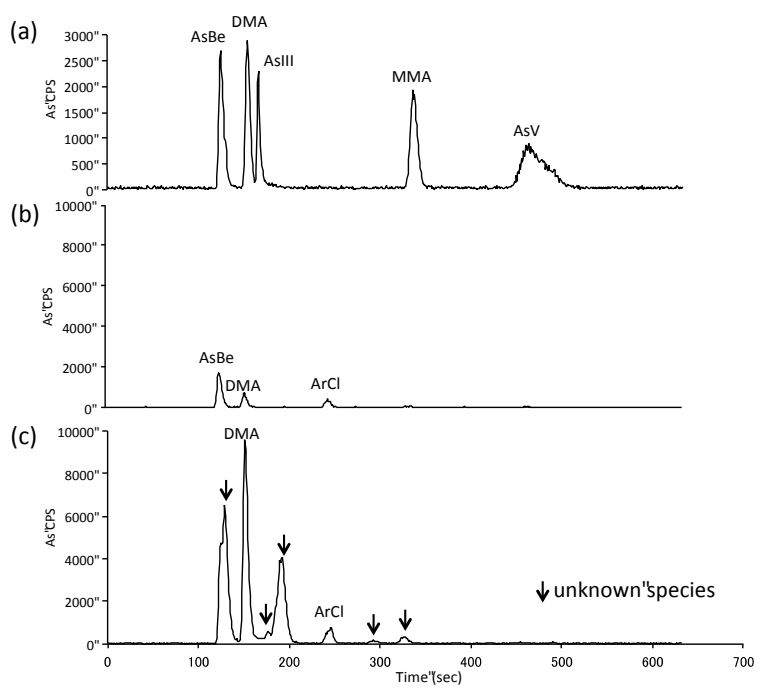

Fig.3 Chromatogram of arsenic standard solution (a) and urine sample before (b) and after (c) wakame ingestion using HPLC-ICP-MS

Arsenic in urine after wakame seaweed ingestion analyzed by HPLC-ICP/MS and HPLC-MS/MS

Five volunteers ingested $300 \mathrm{~g}$ of wakame seaweed each. The participants ingested $593.7 \mu \mathrm{g}$ of arsenic in total, and $176.3 \pm$ $65.2 \mu \mathrm{g}$ of arsenic were detected in their urine, meaning that $30 \%$ of the ingested arsenic was excreted in the urine during the 5-day period. In contrast, when a male ingested water containing synthesized AsSug328 (1220 $\mu \mathrm{g}$ of arsenic), approximately $80 \%$ of the arsenic was excreted in urine over 4 days (Francesconi et al., 2002). In our study, 5 volunteers ingested seaweed containing AsSug so that arsenic could be mainly excreted in the feces. The difference in the urinary excretion rate appeared to be due to the difference in intake method.

A chromatogram of urinary arsenic speciation analysis is illustrated in Fig. 4. Five compounds were detected; the major peak correlated with DMA, but other peaks did not correlate with the arsenics detected in wakame seaweed. DMA content was $58.1 \pm 5.0 \%$ of T-As. Since AsSug328 comprises approximately $90 \%$ of the arsenic in wakame seaweed extract, it is presumed that a greater portion of the urinary DMA is AsSug328. These results agreed with those of an earlier report (Francesconi et al., 2002) in that the major metabolite was DMA since it constituted $67 \%$ of the total arsenic excreted following synthesized AsSug328 ingestion.

The maximum DMA excretion rate was $2.14 \mu \mathrm{g}$ arsenic/h at $24 \mathrm{~h}$ after wakame seaweed intake. The DMA excretion rate before intake was $0.38 \mu \mathrm{g}$ arsenic/h. Urinary DMA fell to the level before wakame intake $95 \mathrm{~h}$ after ingestion. The biological half-time (BHT) of DMA in urine is $13.4 \mathrm{~h}$, a figure that was calculated using the values obtained from 24 to $44 \mathrm{~h}$. Francesconi et al. (2002) also reported that the excretion rate peaked between 22 and $31 \mathrm{~h}$, and the BHT of DMA was 
estimated to be $14 \mathrm{~h}$. Our results accorded well with theirs, meaning that metabolism of AsSug does not have racial differences.

\section{Conclusion}

The total arsenic concentration of the wakame seaweed was $34.3 \pm 2.1 \mu \mathrm{g}$ arsenic/g. The best method for arsenic extraction from wakame seaweed was bead beating after cellulase treatment, the rate of which was $92 \%$. Three peaks were detected in speciation analysis of the wakame seaweed, and 2 of them were the major peaks for AsSug328 and AsSug482. Five volunteers ingested $593.7 \mu \mathrm{g}$ of arsenic, and 176.3 \pm 65.2 $\mu \mathrm{g}$ of arsenic were detected in the urine over a 5-day period. The major metabolite, DMA, comprised approximately $60 \%$ of the detected arsenic. The BHT of DMA is estimated to be 13.4 h.

\section{Acknowledgements}

This work was supported by a Grant-in-Aid for Scientific Research (23390165) from the Ministry of Education, Culture, Sports, Science, and Technology of Japan.

\section{References}

IARC. Some drinking water disinfectants and contaminants, including arsenic. IARC Monographs on the Evaluations of Carcinogenic Risks to Humans 2004;84:36-267.

Vahter M. Mechanisms of arsenic biotransformation. Toxicology 2002;181-182:211-7.

Yamanaka K, Kato K, Mizoi M, An Y, Takabayashi F, Nakano
M, et al. The role of active arsenic species produced by metabolic reduction of dimethylarsinic acid in genotoxicity and tumorigenesis. Toxicol Appl Pharmacol 2004;198:385-93.

Mizoi M, Takabayashi F, Nakano M, An Y, Sagesaka Y, Kato $\mathrm{K}$, et al. The role of trivalent dimethylated arsenic in dimethylarsinic acid-promoted skin and lung tumorigenesis in mice: tumor-promoting action through the induction of oxidative stress. Toxicol Lett 2005;158:87-94.

IARC. Agents Classified by the IARC Monographs, Volumes 1-100. In. Lyon; 2010.

Kirby J, Maher W, Spooner D. Arsenic occurrence and species in near-shore macroalgae-feeding marine animals. Environ Sci Technol 2005;39:5999-6005.

Taleshi MS, Edmonds JS, Goessler W, Ruiz-Chancho MJ, Raber G, Jensen KB, et al. Arsenic-containing lipids are natural constituents of sashimi tuna. Environ Sci Technol 2010;44:1478-83.

Francesconi KA, Tanggaar R, McKenzie CJ, Goessler W. Arsenic metabolites in human urine after ingestion of an arsenosugar. Clin Chem 2002;48:92-101.

Schmeisser E, Goessler W, Francesconi KA. Human metabolism of arsenolipids present in cod liver. Anal Bioanal Chem 2006;385:367-76.

Shimoda Y, Suzuki Y, Endo Y, Kato K, Tachikawa M, Endo G, et al. Speciation analysis of arsenics in commercial Hijiki by high performance liquid chromatography-tandemmass spectrometry and high performance liquid chromatography-inductively coupled plasma mass spectrometry. J Health Sci 2010;56:47-56. 